\title{
Investigación y gestión de la investigación: reflexiones, retos y transformaciones
}

Miguel Barahona ${ }^{1}$

\section{Introducción}

Investigación y gestión de la investigación, semánticamente estos dos términos hacen acopio al trabajo que siempre debe realizar cada uno de los investigadores universitarios. El hecho de investigar es un proceso intrínseco propio de la formación académica y requiere un conocimiento previo. El mismo proceso debe ser planificado a base de la integración y consolidación de las prioridades investigativas institucionales. La suma de estas actividades durante el proceso investigativo genera una sinergia culminando con una serie de resultados que visibilizados aportan un cúmulo de nuevos y útiles conocimientos.

Pero en el campo de las investigaciones en el área de las ciencias sociales, específicamente al interior de las humanidades y las artes, existe una especie de inflexión, pues al no pertenecer a las ciencias exactas, las investigaciones deben orbitar alrededor de lo cualitativo y las propuestas de proyectos investigativos deben ser formuladas desde la aproximación teórica humanística dentro de las áreas de especialización del núcleo de los profesores investigadores. Al mismo tiempo dichas investigaciones deben enarbolar el gallardete de la interdisciplinariedad relacionándola e integrándola directamente con otros pares investigadores dentro de nuestra Alma Máter.

El camino de la investigación ligado a las ciencias de las humanidades y las artes en la UNAH ha tenido sus valladares, pues parafraseando las aciagas palabras de Mario Vargas Llosa $(1990,176)$ quien en su momento las abordó desde el quehacer literario y nosotros ahora las aplicamos al campo de la investigación científica. De esta manera se puede decir que:

\footnotetext{
${ }^{1}$ Profesor investigador, Escuela de Letras, Facultad de Humanidades y Artes, UNAH. Tegucigalpa DC, Honduras C.A mbarahona@unah.edu.hn
} 
"A finales del siglo XX y a comienzos de la primera década del siglo XXI por regla general el docente investigador en nuestro país, por aquel tiempo tan funesto para la ciencia, este investigaba en condiciones excepcionalmente difíciles, porque a lo interno la institucionalidad por regla general se había montado un frío, casi perfecto mecanismo para desalentar y matar en él o en ella la vocación. Dicha vocación, ayer y hoy es hermosa, absorbente y tiránica, y reclama de sus adeptos una entrega total. La pregunta que atañe aún hoy en día sobre la vocación es la siguiente: ¿Cómo este docente pudo hacer de la investigación un destino, una militancia? Pues se rodeaba de entes que, en su mayoría, no sabían apreciar la investigación o en su defecto no les daba la gana de investigar. Sin mecenazgo, en un ambiente académico que no lo azuzara y exigiera, el investigador fue aquel que libró y salió victorioso en las mil batallas..."

Llegada la segunda década del presente siglo, la realidad de los profesores investigadores de la UNAH cambia diametralmente y de forma positiva, dado que la propia institución crea y empodera un ente especializado. Igualmente, genera distintas vías que entregan como herramienta a los docentes investigadores y en igualdad de condiciones, el aprovechamiento general de los recursos disponibles de índole académico y financiero. Además, la misma institucionalidad adecua la continua capacitación con la puesta en marcha de distintos programas de formación orientados estrictamente a la investigación universitaria.

La UNAH a través de la DICYP permite centrarse en el éxito de las investigaciones generando a lo interno de la UNAH diversos espacios de visibilización y divulgación de los trabajos fruto de los proyectos investigativos mediante los institucionalizados congresos de investigación científica: de igual forma, permite otro tipo de visibilización: la escritural, por medio de publicaciones periódicas editadas en dos revistas científicas indexadas.

El presente escrito orbita sobre la investigación y la gestión de la investigación por medio de la propia experiencia del modelo vivido por los docentes investigadores de la Facultad de Humanidades y Artes de la UNAH, quienes desde el año 2008 han hecho del quehacer investigativo parte de su vida académica. De esta forma, se presenta toda una articulación experiencial esbozada en cuatro apartados:

1. Un acercamiento a la formación del primer Grupo de Investigación Filológica de la Facultad de Humanidades y Artes de la UNAH. Aquí se detalla cierta carencia detectada por los investigadores al interior de su unidad académica, relativa directamente a las opciones en cuanto a realizar una investigación científica que fuese reconocida y apoyada institucionalmente. En este apartado se puntualizan los procesos de integración realizados por los mismos investigadores, dando 
como resultado la formación y acreditación del primer Grupo de Investigación de la Facultad de Humanidades y Artes.

2. Una reflexión en torno a la gestión de la investigación: Redes universitarias y la obtención de fondos. El caso del proyecto "La universidad de la calle: las imágenes del grafiti". Este subtema contempla la importancia de la formación de redes académicas interuniversitarias y transfronterizas. Fue a través del intercambio experiencial focalizado en un proyecto de investigación realizado por medio de una red de investigadores conformada por profesores de la UNAH, UNITEC y Universidad Nacional de Jujuy, Argentina. De igual forma, se aborda la importancia en lo relativo al proceso de la obtención de fondos externos para visibilizar los resultados finales de la investigación realizada.

3. Los congresos científicos de la UNAH y su virtual incidencia en la visibilización de proyectos del Grupo de Investigación Filológica de la Facultad de Humanidades y Artes 2008-2015. Para acompañar la producción investigativa es necesaria la propia divulgación, tanto a lo interno, como a lo externo de la institución. Nosotros creemos firmemente que los grupos de investigación siempre deben transmitir su experiencia y el ámbito académico por excelencia para este fin lo constituye la activa participación en congresos científicos. Aquí se resume con base en temas de trabajos y proyectos de investigación, en una línea del tiempo todas las participaciones de nuestros investigadores en los distintos congresos científicos auspiciados por la DICYP-UNAH.

4. Entorno a la visibilización de las investigaciones científicas por medio de las publicaciones. En este cuarto apartado se valora la premisa de que publicar las experiencias de investigación afianza las estrategias para la redacción científica efectiva, lo cual conduce al fortalecimiento de la confianza del autor. Aquí se destacan las meritorias publicaciones realizadas por nuestros investigadores, quienes desde el año 2010, hasta la fecha, han publicado en las dos revistas científicas de la DICYP. De igual manera, se hace acopio a la publicación de trabajos académicos en otras revistas especializadas y también se detalla la edición y publicación de libros que visibilizan distintas investigaciones temáticas del Grupo de Investigación Filológica de la UNAH.

El ámbito de todo nuestro escrito, expresado en estos cuatro apartados, se puede resumir escribiendo en paráfrasis lo expresado en su momento por René Descartes: investigo, publico y luego existo. 


\section{A. Un acercamiento a la formación del primer Grupo de Investigación Filológica de la Facultad de Humanidades y Artes de la UNAH}

Considerando que ya muy encaminados los albores del siglo XXI y entrada la segunda década del mismo, todavía a lo interno de nuestra Facultad no se generaban investigaciones científicas grupales que reflejaran la propia capacidad inter y multidisciplinaria de trabajos que involucraran directamente a estamentos de las distintas escuelas y departamentos que conforman la Facultad de Humanidades de la UNAH. Esta situación no discurre entre nosotros los investigadores como una falencia; al contrario, se determina como la excelsa oportunidad de empoderar investigaciones y proyectos científicos pertinentes al interior de los distintos departamentos y escuelas que conforman nuestra Facultad. Así, en su momento surgen ciertas interrogantes:

1. ¿Se puede potenciar la investigación científica involucrando a las distintas Escuelas de la Facultad de Humanidades y Artes de la UNAH?

2. ¿Dentro de cual ámbito investigativo se podrían realizar las mismas investigaciones?

3. ¿Existirá una ciencia que empodere la investigación inter o multidisciplinar dentro del campo de las Humanidades y las Artes?

Tratando de fundamentar un asidero teórico para contestar las interrogantes e inspirar un pensamiento crítico en su momento se estudia la propuesta de Rafael Cano (1992, 93), autor que aborda la temática de una ciencia dentro del ámbito pertinente aplicado a las investigaciones dentro del campo de las humanidades y las artes bajo el siguiente argumento científico:

"...es cierto que la Filología es una ciencia, o disciplina intelectual, cuyo ámbito de trabajo son los textos escritos, todo análisis de textos, de una u otra forma, caerá dentro de su radio de acción, y será pues una actuación más de la ciencia filológica. En otro caso habrá de entender que en análisis filológicos es uno de los modos posibles de analizar textos, junto a, por ejemplo, análisis histórico u otros, en especial análisis lingüísticos y análisis literario, modos con que la relación ha sido históricamente más estrecha, y la diferenciación, por tanto, más difícil...es a costa de convertir la Filología en una especie de disciplina universal..." (Cano, 1992,93).

Las interrelaciones de la ciencia filológica esbozadas en las palabras de Cano, generan dentro de sí un esquema categorial que promueve las principales áreas de estudio a lo interno de nuestra Facultad de Humanidades y Artes. De hecho, una investigación científica que orbite dentro de la ciencia filológica es del todo incluyente 
y Cano lo arguye de la siguiente manera: "La Filología como ciencia y disciplina que estudia el lenguaje para penetrar una cultura, por ello las disciplinas como la sociolingüística, lingüística, lingüística antropológica, psicolingüística, etc., constituyen las actuales filologías sincrónicas...como ciencia interpretativa, más que descriptiva-hermenéutica, la filología ha de poner en juego todos los mecanismos que permitan entender debidamente un enunciado, por mínimo que sea"(1992,94).

Considerando las ideas de Cano, se reflexiona por nuestra parte y se decide tomar como eje central del estudio investigativo la ciencia filológica, pues la misma proporciona una plataforma general para realizar estudios y proyectos de investigación destinados a reunir y encomiar varias escuelas y departamentos pertenecientes a la Facultad de Humanidades y Artes.

A mediados del año 2014 se integra e inscribe en la DICYP el Grupo de Investigación Filológica de la UNAH, cuya pertinencia investigativa estriba en primer término el de realizar investigaciones de la literatura de viajes escrita sobre Honduras en los siglos XIX y XX.

Fundamentada la línea investigativa filológica y siguiendo la congruencia entre la pertinencia y los objetivos del Grupo de Investigación, surge el momento de interrogarnos: ¿Cuán necesario sería articular y determinar sobre el carácter de nuestras investigaciones? Pues de hecho faltaba determinar el modelo a seguir en un camino que se bifurcaba dentro del carácter investigativo de índole inter o multidisciplinar. Así ante tal vacío, buscamos el consabido y necesario asidero teórico y recurrimos a Mario Tamayo $(1993,70)$ quien en su momento nos orienta en el sentido de la aplicación de las interacciones investigaciones:

"El prefijo inter (entre) indica que entre las disciplinas se va a establecer una relación un tipo de relación que nos conduce a un estudio...la interdisciplinaridad se presenta entonces como connotación de aspectos específicos de la interacción de las disciplinas que dentro del conjunto adquiere un sentido...la interdisciplinariedad es el conjunto de disciplinas conexas entre sí y con relaciones entre sí a fin que sus actividades no se produzcan de forma aislada dispersa y fraccionaria".

Caracterizada la interdisciplinariedad al interior del Grupo de Investigación Filológica, se aborda como tema principal una temática de investigación que considere específicamente el tema de los escritos viajeros, pero con la variante de estudiarlos dentro del espacio investigativo desde la óptica de la literatura, la lingüística, la traducción, la lexicografía y las artes, adscribiéndose a la misma otras ciencias perti- 
nentes que admite nuestro marco filológico, como lo pueden constituir el derecho, la economía y, por supuesto la historia.

Para finalizar este apartado, se puede resumir que el Grupo de Investigación Filológica de la Facultad de Humanidades y Artes se mantiene activo hasta la actualidad conforme al seguimiento permanente y disciplinado resumido en cuatro estrategias de trabajo:

1. La caracterización del Grupo de Investigación, tomando como referencia la investigación de índole filológica e interdisciplinaria.

2. Definición de los temas de investigación referidos intrínsecamente a los objetivos del grupo de investigación relacionados directamente con las competencias que posee cada uno de los investigadores.

3. Las propuestas de proyectos, la búsqueda y gestión de fondos en tiempo y forma.

4. La autoevaluación que implica la revisión constante del cumplimiento de nuestros objetivos basados en el trabajo individual a través de productos escriturales generados dentro de un espacio de tiempo determinado.

\section{B. Una reflexión en torno a la gestión de la investigación: redes universitarias y la obtención de fondos. El caso del proyecto: "La universidad de la calle: las imágenes del Grafiti"}

Sonia Reynaga y Pedro Farfán $(2004,4)$ al hablar en torno a las redes académicas indican lo siguiente:

"La red académica, puede concebirse como un mecanismo de apoyo, de intercambio de información y una comunidad de comunicación horizontal, cuya base es una red social, un tejido, una madeja compleja en la que se sinergizan a través de interacciones entre vínculos dinamismos, intereses, fuerzas, energías y puntos de apoyo y encuentro (nodos), con el propósito principal de dialogar, encontrar respuestas, construir conocimientos y unirse en la búsqueda o creación de soluciones respecto a una temática 0 problema. La importancia de una red, sobre todo de una red académica, es enorme porque permite a los académicos trabajar con flexibilidad, cooperativamente, en el desarrollo académico, científico, técnico, social y cultural en una comunidad, equipo, grupo 0 región. Permite la integración para la solución de problemas y temáticas comunes, extiende beneficios a funcionarios, educadores, profesores... facilita el intercambio de datos, información, conocimiento, y propicia la reflexión..."

Las palabras de Reynaga y Farfán atisban en contra del formalismo endógeno que 
se puede arraigar dentro de ciertos círculos universitarios de investigación científica, ambos autores exteriorizan dentro del contenido de las ideas la importancia que debe tener para nosotros los investigadores el hecho de formar parte de una red académica.

Se puede resumir que el valor intrínseco en la formación de las redes académicas se da dentro de los siguientes aspectos: la concepción individual o grupal del compromiso como parte de la consabida actitud consciente del voluntariado entorno a la investigación científica. Suma también el medio y la herramienta de asociación en apoyo y el crecimiento del conocimiento. Además, la red por sí misma construye y fomenta el intercambio de las ideas y de los conocimientos previos, además genera un cúmulo experiencial obtenidas en relación al campo de las presentes y de las futuras investigaciones, propiciando la evolución del pensamiento científico reflejado en la crítica constructiva y potenciando al mismo tiempo más temas de investigación. Evocando la investigación científica realizada por medio de redes académicas y resaltando un ejemplo dentro de la propia experiencia. A continuación hablaremos sobre el proyecto de investigación realizado en el año 2011, cuya temática central gira alrededor del grafiti en Tegucigalpa. Dicho proyecto de investigación fue concebido a finales del año 2009, en Valparaíso, Chile, cuando un profesor investigador de la Facultad de Humanidades y Artes de la UNAH viaja a la Pontificia Universidad Católica de Chile gracias al apoyo de fondos de la entonces Dirección de Investigación Científica (DICU) y participa como ponente dentro de dos mesas de trabajo de índoles interdisciplinarias, en las cuales se abordan distintas temáticas de investigación social, teniendo como el eje temático común las ciudades latinoamericanas.

En Valparaíso, el profesor hondureño se reúne con la Unidad de Investigación Semiótica "La universidad de la calle" adscrita a la Universidad Nacional de Jujuy (UNJu), Argentina, cuyo director por esa época era el profesor e investigador Juan Ángel Magariños de Morentin. El investigador hondureño conoce de primera mano la base de la investigación semiótica que realiza dicha unidad de investigación de la Universidad Nacional de Jujuy, cuyo trabajo gravita en el siguiente fundamento:

"Universidad de la Calle se refiere a esa suma de conocimientos que no se imparte en ninguna institución determinada, sino que se adquiere en el esfuerzo cotidiano por ganarse la vida y/o por tener éxito en el logro de las metas sociales. la etapa de la Investigación tiene como objetivo la recopilación de la información pertinente que consistirá fundamentalmente en: (1) la enunciación descriptiva de un conjunto de comportamientos generadores de experiencia, percibidos y/o protagonizados por el propio investigador, o acerca de los cuales otra persona le haya proporcionado infor- 
mación; (2) la enunciación generalizadora del conocimiento experiencial adquirido por el investigador a partir de la percepción de, participación en, o testimonio trasmitido acerca de dichos comportamientos. Esto permitirá identificar la efectiva existencia, fuera de los procesos pedagógicos formales e informales, de concretas situaciones de aprendizaje con fundamental importancia en el logro de los objetivos de mejoramiento social e, incluso, de supervivencia (Magariños, 2009,5).

Dicho fundamento teórico del Proyecto "La universidad de la calle", hace para el participante nacional comprensible y tangible la idea de realizar investigación social aplicada. Al retornar a Honduras, el profesor junto a otro colega valoran positivamente la oportunidad de hacer un estudio dentro del marco de la investigación semiótica. Al abordar los lineamientos investigativos proporcionados por "La Universidad de la calle" se genera una propuesta formal de un proyecto. Así nace la idea de abordar el proyecto de investigación ligado al estudio del grafiti en Honduras, particularmente el de la ciudad capital.

De inmediato nuestros investigadores de la UNAH proceden a conformar una red interuniversitaria de investigación conformada por ellos mismos, sumando a dos profesores investigadores quienes en su momento laboraban en una universidad privada de Tegucigalpa. El trabajo de investigación se orienta específicamente a estudiar el grafiti en Tegucigalpa Honduras, reconociendo al interior del proyecto el presupuesto que hasta ese momento dicha expresión artística no se había estudiado en nuestro país y los investigadores realizan la articulación del estudio basado en la siguiente premisa:

"Las imágenes del grafiti. Enunciación, narratividad y espacio, estudiará el grafiti como una forma de comunicación integrada desde hace varios años dentro del paisaje urbano de Tegucigalpa...El grafiti proviene de voces anónimas surgidas al margen de los espacios legitimados y los autores lo utilizan como una expresión crítica... Es la misma condición del grafiti como un género por antonomasia discursivo e hibrido mismo que conjuga lo verbal e icónico, hace posible realizar un estudio visto desde diversas teorías pertenecientes a las ciencias del lenguaje..."(Barahona, 2011, 6-7).

Para mediados de 2010, el proyecto del grafiti ya forma parte de la Unidad de Investigación de la UNJu "La universidad de la calle", justo en el mes de enero del año siguiente comienza la primera fase de la investigación ejecutada por un grupo de trabajo interdisciplinario, interuniversitario y transfronterizo; compuesto por dos investigadores de la Facultad de Humanidades y Artes de la UNAH, dos investigadores de la Facultad de Humanidades de UNITEC y una investigadora de la Facultad de Comunicación de la Universidad Nacional de Jujuy, Argentina. 
El proyecto se estructura en tres momentos: La creación de una red de investigadores interuniversitaria, conformada por profesores investigadores cuya actividad sea estrictamente voluntaria y que además estén en plena disponibilidad para dedicar el tiempo y disciplina de trabajo al proyecto; el segundo momento se da con la organización de la investigación con fechas y productos concretos escriturales dentro de la propia especialidad de cada participante y, por último, la presentación de resultados finales de la investigación.

La experiencia de los investigadores al integrar y trabajar en redes académicas de investigación se puede resumir en las palabras de Reynaga y Farfán $(2004,2)$ :

"En referencia la red académica, puede concebirse como un mecanismo de apoyo, de intercambio de información y una comunidad de comunicación horizontal, cuya base es una red social, un tejido, una madeja compleja en la que se sinergizan -a través de interacciones entre vínculos- dinamismos, intereses, fuerzas, energías y puntos de apoyo y encuentro (nodos), con el propósito principal de dialogar, encontrar respuestas, construir conocimientos y unirse en la búsqueda o creación de soluciones respecto a una temática o problema..."

En cuanto a los procesos de la investigación sobre el grafiti en Tegucigalpa se identificaron dos etapas: el trabajo de campo que fue distribuido a partir del estudio de los espacios utilizados por los autores grafiteros en Tegucigalpa y surge la apropiación en el mismo lugar de las obras del arte callejero. La segunda etapa incluye el estudio y la categorización de las obras, realizado por medio del abordaje teórico de los investigadores del proyecto a través de la escritura de artículos científicos.

Para finales del año 2011, se concluye la investigación interdisciplinaria, misma que se enfocó desde la perspectiva de: la historia del arte, el diseño gráfico, las artes y la fotografía, la lingüística, la ciencia de la comunicación y la semiótica; dicha dinámica de estudio generó los siguientes artículos científicos:

1. Notas para el estudio sociológico del grafiti.

2. Anonimato y marginalidad en el objeto de arte.

3. La decodificación semiótica del grafiti: espacio y lenguaje.

4. Una lectura semiótica del grafiti.

5. Grafiti urbano: entre el arte y la barbarie.

La investigación por sí misma permitió descubrir que el grafiti en Tegucigalpa: "No solo es un enunciado. Las circunstancias de producción, la diversidad de las obras en los espacios urbanos, el producto en sí mismo, el sujeto que lo ejecuta, la intenciona- 
lidad y las estrategias empleadas...sitúan a esta práctica dentro del género discursivo y su riqueza radica en el uso de un doble lenguaje el verbal y el icónico..." (Barahona, 2011, 8).

Pero, de hecho, ¿de qué sirve una investigación científica si los propios resultados del estudio no se visibilizan? Mikhail Benet Rodríguez junto a otros investigadores cubanos, manifiestan el principio de la investigación científica, indicando los procesos y asimilando el múltiplo que se puede lograr alcanzar al visibilizar la misma investigación a través de resultados concretos. He aquí el abordaje de los investigadores caribeños:

"Mediante la actividad científica y aplicando los métodos de la ciencia, los investigadores generan y aprueban nuevos conocimientos y tecnologías que después se exponen en revistas, libros y otras publicaciones para que estén al alcance de todos. Esto garantiza que se formen nuevos profesionales con conocimientos suficientes para desarrollar la sociedad y a su vez nuevos conocimientos según el ciclo: conocimiento, divulgación de conocimiento, utilización de conocimientos en la formación de profesionales, investigación y construcción de nuevos conocimientos...se debe llamar llamar la atención sobre este importante problema existente, para que los investigadores se preocupen en organizar la búsqueda de financiamiento para la ejecución de sus proyectos de investigaciones y la introducción y divulgación de sus resultados. Así como para que los administrativos (personas con poder de decisión), "descubran" la importancia de organizar bien el financiamiento de la ciencia y apoyen decisivamente su cumplimiento $(2010,1)$.

Lo anterior denota que toda investigación científica no solo debe generar un conocimiento, también de forma implícita debe contener la premisa de visibilizar y compartir el mismo conocimiento sumando las experiencias adquiridas, de igual forma los investigadores deben buscar que sus trabajos trasciendan y se visibilicen en otras instancias dentro de espacios académicos nacionales e internacionales.

En cierta manera, los resultados finales de nuestra investigación semiótica sobre el grafiti en Tegucigalpa fueron visibilizados en Jujuy, Argentina, cuando se hizo la entrega final del proyecto; pero en Honduras para todos los investigadores involucrados en el mismo la visibilización y divulgación del proyecto se constituyó en la ardua tarea pendiente de realizar.

Considerando que los exiguos fondos reunidos para ejecutar la investigación no contemplaron la publicación impresa. Tratando de obtener fondos para lograr la publicación de nuestra investigación, se recurre a la Agencia Española de Cooperación internacional (AECID) y al Centro Cultural España en Tegucigalpa (CCET), entes de 
cooperación acreditados en Honduras, quienes de hecho se interesan por divulgar los resultados del proyecto, pero al mismo tiempo ambas instituciones se empeñaron en dictar ciertas pautas dentro la prerrogativa de financiación no reembolsable y la virtual adecuación del uso de los fondos a conceder deberían estar dirigidos hacia tres modelos de visibilización y de divulgación de resultados, los cuales se desarrollarían a través de inquebrantables lineamientos institucionales:

1. Conferencias públicas sobre los procesos de la investigación científica en el ámbito del estudio del grafiti. Estas debían ser expuestas por todos los investigadores involucrados en el proyecto.

2. Montaje en el CCET de una exposición visual de las imágenes del grafiti.

3. La edición de un libro homónimo del proyecto de investigación bajo el sello editorial de la AECID, además de hacer efectiva la entrega de ciertos ejemplares del libro a distintas entidades educativas de Honduras, Centroamérica, Argentina y España.

El logro de la concesión de fondos económicos por parte de la cooperación internacional se obtuvo mediante la presentación de una propuesta formal y la pertinencia de seguir todos los protocolos impuestos por el ente facilitador de los fondos económicos.

La propuesta y el desarrollo del proyecto de investigación sobre el grafiti en Tegucigalpa, cuya concepción y estructuración dejaron a los investigadores directamente involucrados un cúmulo de experiencias, las cuales se pueden resumir así:

1. Un enfoque interdisciplinario del estudio semiótico, abordado por una red de investigadores.

2. La perspectiva local y extra regional, reflejada en la participación directa de los investigadores de Honduras y la investigadora de la República de Argentina.

3. La visión integradora utilizada en la propuesta y en realización del proyecto caracterizada por la distinta formación académica de cada uno de los investigadores.

4. La articulación del proyecto cuyos componentes se dio en tres momentos: apropiación teórica metodológica, tareas investigativas conforme al campo de trabajo de cada investigador y los productos finales reflejados en artículos científicos.

5. La búsqueda y gestión de fondos para la visibilización y divulgación de los resultados del proyecto, lograda por medio de una propuesta basada en los requerimientos indicados por la AECID y al final se entregó como producto tangible la edición y publicación de un libro. 


\title{
C. Los congresos científicos de la UNAH y su virtual incidencia en la visibiliza- ción de proyectos del Grupo de Investigación Filológica de la Facultad de Humanidades y Artes, 2008-2015
}

Ante la pregunta: para qué sirve un congreso científico, Jorge Everardo Aguilar Morales $(2013,2-3)$ propone la siguiente respuesta:

\begin{abstract}
"Los congresos y las revistas científicas son el espacio para hacer públicos nuestro descubrimientos, dialogar con nuestros colegas y recibir retroalimentación que nos permita mejorar nuestro trabajo, al comentar nuestro trabajo de investigación con otras personas, observamos aspectos que no se habían tomado en cuenta o que requieren mayor elaboración y surgen nuevas ideas para futuras investigaciones, de la misma forma si el ambiente es propicio, podemos establecer lazos de cooperación con personas, grupos e instituciones que nos permitan optimizar los recursos disponibles que tenemos y aumentar la visibilidad de nuestro trabajo. Para muchos, un congreso científico sirve conocer gente con la cual se pueda trabajar y establecer un contacto personal directo con otros investigadores, es también una función importante de un congreso. Una ventaja adicional de un encuentro de investigadores es que permite mantenerse al día con los avances más recientes e interactuar directamente con los profesionales con mayor experiencia en un campo de conocimiento, sin embargo, lograr que las personas trabajen de manera colaborativa no es nada sencillo, pero los congresos además de ser obviamente una actividad científica son sobre todo una actividad social y como tal facilitan la aparición de roles sociales compatibles con el trabajo colaborativo..."
\end{abstract}

Para potenciar los resultados de una investigación es necesario garantizar la visibilización de la misma concretamente a través de estas tres vías: participación en congresos científicos (nacionales e internacionales), publicación en revistas especializadas e indexadas y edición y publicación de libros. A continuación se detallan dichas vías de visibilización:

1. Participación en congresos científicos. Resulta clave el aporte de la visibilización de las investigaciones que permita dar a conocer los resultados de las mismas. Aguilar Morales responde a la pregunta ¿Cuándo es recomendable asistir a un congreso científico?:

"Aunque en la vida profesional es importante asistir de manera continua a eventos científicos, se aprovecha al máximo la asistencia a un congreso cuando se tiene un trabajo de investigación que presentar. Todos los profesionistas deberíamos esforzarnos por abandonar el rol de espectadores y convertirnos en actores protagónicos en el avance de nuestra profesión. Es importante recordar que una intervención profesional concluye solamente hasta que se documentan las intervenciones profesionales realiza- 
das. Si hacemos nuestro trabajo de manera sistemática siempre tendremos material para participar como ponentes en este tipo de eventos Entre más temprano se adquiera

el hábito de asistir a eventos científicos mayores serán los beneficios que se obtengan". (2013, 3-4).

De esta forma, se puede resumir que los investigadores de la red académica, Grupo de Investigación Filológica, han cumplido a cabalidad lo indicado en el párrafo anterior, pues a lo largo de los años, comenzando desde el año 2008 hasta la fecha, cada uno de sus miembros siendo profesores de la Escuela de Letras, Escuela de Artes y la Escuela de Lenguas y Culturas Extranjeras, han presentado distintas ponencias que giran alrededor de las investigaciones, las cuales han sido visibilizadas hasta el día de hoy en los distintos congresos científicos de la UNAH. Los trabajos presentados por nuestros investigadores se pueden resumir así:

a. 2 Congreso de Investigación Científica UNAH 2008

1) Panel 1: El arte de viajar con la palabra (viajeros por Centroamérica en el siglo $\mathrm{XIX).}$

2) Panel 2: El último rezador (investigación y videografía sobre los rezadores étnicos lencas de Yamaranguila, Intibucá, Honduras).

b. 3 Congreso de Investigación Científica UNAH 2009

1) Panel 1: Espacios de identidad. Una visión reflexiva sobre la identidad nacional abordada por los viajeros del siglo XIX.

2) Panel 2: Una función con móviles y tentetiesos de Marcos Carías o la tensión entre la modernidad y postmodernidad en escritura narrativa.

c. 4 Congreso de Investigación Científica UNAH 2010

1) Panel 1: El viaje como iniciación de la memoria (espacios, viajes e identidad en la literatura de viajes)

2) Panel 2: Interacciones, instrumentos y miradas. Objetos y fenómenos del arte posmoderno en Honduras.

d. 5 Congreso de Investigación Científica UNAH 2011

1) Panel 1: Las imágenes del grafiti: enunciación, narratividad y espacio (Proyecto de investigación: "La universidad de la calle", Universidad Nacional de Jujuy, Argentina). 
2) Panel 2: La construcción del paisaje, narración y experiencia de viajeros extranjeros que recorren Honduras a finales del siglo XIX y principios del XX.

3) Panel 3: El archivo fotográfico Juan Pablo Martell: patrimonio de imágenes, rescate, conservación y difusión de los archivos fotográficos.

4) Panel 4: Metamorfosis simbólicas de cuerpos fragmentados en el registro imaginario de la literatura centroamericana.

5) Panel 5: Antonio de Irisarri y su preocupación filológica en el cristiano errante: el buen uso del español.

e. 6 Congreso de Investigación Científica UNAH 2012

1) Panel 1: La utilización de los archivos fotográficos Juan Pablo Martell en la construcción de la identidad nacional.

2) Panel 2: La visión íntima en Exploraciones y Aventuras por Honduras: Imágenes de una narrativa fragmentada.

3) Panel 3: El futuro de los rezadores de Yamaranguila. Un acercamiento a los ritos agrarios y del hogar presentes en los rezadores étnicos lencas.

4) Panel 4: Subjetividad en la literatura de viajes: la construcción del paisaje en los viajeros por Honduras siglos XIX -XX.

5) Panel 5: Ciudad de Guatemala: el escenario en Limbo de Javier Payeras.

f. 7 Congreso de Investigación Científica UNAH 2013

1) Panel 1: La construcción del pensamiento viajero: hacia una tipología de la traducción desde los paradigmas de la nacionalidad y la visión cultural.

2) Panel 2: Archivos fotográficos: una propuesta interdisciplinaria para la investigación, promoción y difusión de la identidad nacional.

g. 8 Congreso de Investigación Científica UNAH 2014

1) Panel 1: Análisis histórico del discurso en la literatura viajera centroamericana del siglo XIX.

2) Panel 2: Fototeca digita. El uso interactivo de los archivos fotográficos de la UNAH para la investigación documental.

3) Panel 3: Viajeros por Centroamérica en el siglo XIX, retratos en tinta de la región: una propuesta para la decodificación filológica de la literatura de viajes

4) Panel 4: Problemas más comunes de traducción en la literatura viajera centroamericana en el siglo XIX. 
h. 9 Congreso de Investigación Científica UNAH 2015

1) Panel 1: América Central en la mirada extranjera: exploradores y viajeros entre 1845 a 1898.

2) Panel 2: Percepciones cognitivas lingüísticas del hondureño hacia español de otras naciones.

3) Panel 3: Técnicas y estrategias de la traducción en la literatura viajera centroamericana del siglo XIX.

4) Panel 4: Estado de la lexicografía en Honduras al final del siglo XIX.

5) Panel 5: Honduras: su posición geográfica codiciada desde Hernán Cortés hasta William Vincent Wells.

6) Panel 6: Perspectivas de decodificación en la literatura de viajes dentro del marco de los estudios humanísticos.

7) Panel 7: Fotografía documental en Honduras: La Fototeca Nacional de la UNAH.

i. 10 Congreso de Investigación Científica UNAH 2016

1) Panel 1: Honduras archivo y memoria. La construcción de la identidad en los discursos e imágenes fotográficas de viajeros entre los años de 1910 a 1960.

2) Panel 2: Tegucigalpa: visiones e interpretaciones del paisaje durante los primeros cincuenta años del siglo XX.

3) Panel 3: Copán: viajando en el tiempo y en espacio. Un acercamiento investigativo desde la perspectiva arqueoastronómica y filológica de la cultura maya.

4) Panel 4: Honduras, la gráfica política de la década de los ochentas.

5) Panel 5: Grupo de investigación y realidad nacional: humanidades y artes.

Todas las participaciones de la red académica conformada por investigadores que conforman en la actualidad el Grupo de Investigación Filológica de la Facultad de Humanidades y Artes de la UNAH, han generado en una línea de tiempo determinada los siguientes temas y subtemas investigativos:

a. Tema: Literatura de viajes escrita sobre Honduras y Centroamérica (siglo XIX y $X X)$

1) Subtema 1. Escritura viajera desde la perspectiva del autor.

2) Subtema 2. Identidad nacional y literatura viajes.

3) Subtema 3. Construcción del paisaje en la narrativa de viajes.

4) Subtema 4. Visiones y subjetividades en el fenómeno escritural viajero.

5) Subtema 5. Construcción del pensamiento viajero. 
6) Subtema 6.Decodificación de grabados en la literatura de viajes.

7) Subtema 7. Traductología aplicada a la literatura de viajes.

b. Tema: Narrativa literaria de Honduras y Centroamérica (siglo XX)

1) Subtema 1. Modernidad y posmodernidad.

2) Subtema 2. Estructura filológica en el uso del español.

3) Subtema 3. Lenguaje y comunicación.

4) Subtema 4. Percepciones cognitivas del uso del español.

5) Subtema 5. Simbolismos e imaginarios.

c. Tema: Los archivos fotográficos en Honduras (siglo XX)

1) Subtema 1. Utilización de archivos fotográficos como sinónimo de identidad.

2) Subtema 2. Patrimonio tangible e intangible en las imágenes fotográficas.

3) Subtema 3. Decodificación de los archivos fotográficos.

4) Subtema 4. Modernidad y posmodernidad.

5) Subtema 5. Derechos de autor y conexos en la imagen fotográfica.

6) Subtema 6. Archivos digitales fotográficos y el uso interactivo para la investigación social.

d. Tema: Rezadores étnicos lencas de Yamaranguila, Intibucá (1998-2008)

1) Subtema 1. La visión cosmológica de los rezadores étnicos lencas

2) Subtema 2. Ritos agrarios de los rezadores lencas de Yamaranguila, Intibucá, Honduras.

e. Tema: Grafiti urbano en Tegucigalpa (2011).

1) Subtema 1. Enunciación narratividad y espacio.

2) Subtema 2. Anonimato y marginalidad.

f. Tema: El arte posmoderno en Honduras (Antologías de las Artes plásticas en Honduras (1996-2006).

1) Subtema 1. Interacción artística en los objetos de arte.

2) Subtema 2. Estética y antiestética en el lenguaje artístico posmoderno.

3) Subtema 3. Gráfica y política.

La valoración de las líneas temáticas arriba indicadas, ratifica la pertinencia grupal dentro del orden investigativo interdisciplinario que realiza al interior del Grupo de Investigación Filológica por cada uno de sus miembros. Con esta experiencia investigativa se validan las actividades dentro de la cierta originalidad de concepción, la estructura, realización y divulgación de diversos trabajos de investigación científica. 


\section{Entorno a la visibilización de las investigaciones científicas por medio de las publicaciones}

Gustavo Cáceres Castellanos $(2014,1)$ nos habla de la importancia de publicar los resultados de los trabajos de investigación:

"La investigación científica, entendida como el conjunto de procesos sistemáticos y empíricos aplicados al estudio de un fenómeno, es dinámica, cambiante y evolutiva; puede ser básica, al producir conocimiento y teorías, o aplicada, al resolver problemas prácticos. La divulgación de la investigación científica, mediante artículos, ponencias y conferencias, entre otros mecanismos, es esencial, pues, como comúnmente se reconoce, investigación que no se publica no existe. Se puede decir que la investigación culmina al ser publicada en una revista científica; solo así será conocida por la comunidad académica, sus resultados serán discutidos y su contribución hará parte del conocimiento científico universal".

Considerando el enunciado que dice: investigación que no se publica no existe, pues al interior de la misma articulación del aprendizaje investigativo se considera lo siguiente:

"En la práctica, la ciencia que transmite mejor sus resultados es la más útil, por ello es prioritario comunicar los resultados; la importancia de una publicación científica se puede resumir en contribuir a la construcción colectiva del conocimiento. Cuando se publica un artículo original en una revista científica se hace un aporte a la generación del conocimiento. Se contribuye a que otros investigadores avancen en un campo específico de investigación." (Cáceres, 2014, 2).

De esta forma, los miembros del Grupo de investigación, considerando la premisa de visibilizar y divulgar los resultados de los trabajos y proyectos investigativos en artículos científicos, los cuales han sido transmitidos por medio revistas científicas indexadas; asimismo, otros escritos de investigación que se han divulgado en revistas especializadas. De esta manera podemos indicar que a lo largo de sus años se han logrado divulgar en diferentes publicaciones, distintos escritos científicos cuya autoría forma parte del legado de nuestros investigadores. A continuación se detallan los escritos publicados, haciendo referencia primaria a los entes de divulgación que acogieron los trabajos. 
1. Publicación en revistas indexadas

a. Revista Ciencia y Tecnología

1) Literatura de viajes para la Honduras decimonónica: visiones, invenciones e intervenciones. Representaciones, alteridad y contexto colonialista en exploraciones y aventuras en Honduras (Ciencia y Tecnología, 14, 99-114).

2) El tejido discursivo de una subjetividad: Nota sobre la identidad (Ciencia y Tecnología, 8, 82-91).

3) Travesías e imaginarios urbanos en exploraciones y aventuras en Honduras (Ciencia y Tecnología, 7, 7-62).

b. Revista Portal de la Ciencia

1. La construcción del paisaje en la literatura de viajes en Honduras durante los siglos XIX y XX (Portal de la Ciencia, 8, 123-138).

2. Publicación en revistas especializadas

1. "A propósito del viaje. Analogía y subjetividad en exploraciones y aventuras en Honduras". Yaxkin (25)1, 163-181)

2. A través de Madeira, las Antillas y Centroamérica de Jegór Von Sivers Yaxkin, (25)1, 131-162).

3. Miradas encontradas: estudio de género en El hombre de la guerra, en Trilogía de Centroamérica de Javier Reverte (Istmo, 27. 1-7).

3. Edición y publicación de libros

Valorando la idea potenciada en las siguientes palabras de Gustavo Cáceres (2014:7-8): "Publicar las experiencias de investigación afianza las estrategias para la redacción científica efectiva, lo cual conduce al fortalecimiento de la confianza del autor. ¡A publicar se aprende publicando!". Lo anterior denota un factor agregado, el del planteamiento de objetivos por medio de la visibilización a través de la publicación de libros, esto de hecho favorece el fortalecimiento intelectual de cada uno de los miembros del grupo de investigación, además empodera y estimula la creatividad escritural, desarrolla la capacidad crítica y promueve la formación de un pensamiento fundamentado en una base teórica. La congruencia de la visibilización y la conve- 
niente divulgación de los trabajos de investigación se realizaron por medio de la edición y publicación de los siguientes libros:

1. Retratos de una época de Evaristo López Rojas. Martínez Paúl. (Coord.) Tegucigalpa: UNAH 2015.

2. Juan Pablo Martell Martínez. Fondo Documental de Fotografía. Martínez Paúl. (Coord.) Tegucigalpa: UNAH. 2014.

3. Las imágenes del grafiti: Enunciación, narratividad y espacio. Barahona Miguel. (Coord.) Centro Cultural de España en Tegucigalpa, 2011.

Asimismo aparecen trabajos investigativos publicados como capítulos en los siguientes libros:

1. Martínez, Paúl. (2015). El señor de Salamé. En Miradas al Arte 2014. (38-49). Tegucigalpa, Honduras: CAC-UNAH.

2. Barahona, Miguel. (2015). La utopía retratada en paradojas. De lo particular a lo colectivo en retratos de una época de Evaristo López Rojas. En Martínez Paúl. Evaristo López Rojas. Retratos de una época. (84-121) Tegucigalpa, Honduras: UNAH.

3. Martínez, Paúl. (2015). Una visita a los indios de Guajiquiro, Ephraim George Squier. En Miradas al Arte. (78-89) Tegucigalpa, Honduras: CAC-UNAH.

4. Hernández, Hilcia. (2014). Actitudes lingüísticas en Honduras. Un estudio sociolingüístico sobre el español de Honduras frente al de otros países de habla hispana. En Chiquito, Ana Beatriz y Quesada Pacheco, Miguel Ángel. Actitudes lingüísticas de los hispanohablantes hacia el idioma español y sus variantes (715-792).Noruega: Bergen Language and Linguistic Studies (BeLLS)

5. Martínez, Paúl. (2014). D. José Sotero Lazo, pluma y tinta que retrataron la nación del siglo XIX. En Miradas al Arte. (48-55) Tegucigalpa, Honduras: CAC-UNAH.

6. Martínez, Paúl. (2014). Memorias, medio siglo en fotografías. En Miradas al Arte. (64-71) Tegucigalpa, Honduras: CAC-UNAH.

7. Leyva, Héctor. (Comp.) 2010. Revelar y rebelar. Transición de la modernidad a la posmodernidad en el arte fotográfico hondureño (1990-2009). En Actas del segundo congreso centroamericano de estudios culturales 2009. Tegucigalpa, Honduras: Editorial Acerca.

Este último apartado se puede resumir en las propias palabras de Cáceres Castellanos $(2014,1)$ quien explica la importancia de lo escritural y la consabida publicación 
que se debe hacer en toda investigación científica: "Cuando se escribe un artículo se adquieren y actualizan nuevos conocimientos producto de la revisión del estado del arte, contribuyendo a la formación propia y de los lectores. Por lo tanto, jla publicación científica es una valiosa herramienta que facilita la continuidad en los procesos de educación!"

\section{A manera de conclusión}

La valoración general de este escrito se pude resumir en la pertinencia del quehacer investigativo se debe tomar como parte fundamental en todos los docentes de la Universidad del siglo XXI. Con la misma experiencia investigativa se pueden lograr la integración de resultados individuales y colectivos, mismos que contribuyan a la visibilización y divulgación del quehacer investigativo de la Universidad Nacional Autónoma de Honduras.

En primer lugar, para investigar se requiere la identificación de temas de trabajo afines, de igual manera se deben integrar en el orden de importancia la puesta en marcha de criterios investigativos para garantizar el éxito en la formación de investigadores quienes asociados de forma identitaria pueden formar redes académicas alrededor de la formación de grupos de investigación científica.

Adicionalmente se debe considerar que toda investigación científica representa un aporte colectivo cuya fundamentación inicia desde el estrato teórico conceptual y asimismo reúna a fondo el nivel formativo y experiencial de cada uno de los investigadores, todo con el fin de garantizar la homogeneidad de los resultados logrados a través de la investigación del orden inter o multidisciplinaria. Al mismo tiempo no olvidar que para realizar investigación científica se debe fundamentar en dos pilares: el desarrollo científico y la gestión de la investigación.

Y por último, la caracterización de la investigación científica dentro del campo de las ciencias sociales debe representar a una colectividad, esa que intuye, descubre, relaciona, interpreta, conceptualiza y por supuesto agrupa y gestiona y al mismo tiempo visibiliza escrituralmente ciertas modelizaciones del mundo a partir de los estudios académicos por medio de la ciencia. Se puede concluir que la concepción y estructuración de las investigaciones en el campo de las humanidades y las artes se puede resumir retomando las palabras de Tomás Albaladejo $(1998,75)$ quien de hecho de cierta manera circunscribe el quehacer investigativo a dos espacios: "El ordo naturalis, utilizado para designar la ordenación de los acontecimientos.... y el ordo artificalis u ordo poeticus usado para la disposición artística...". 


\section{BIBLIOGRAFÍA}

Aguilar Morales, Jorge Everardo. (2013). Los congreso científicos. Consejos para contribuir al trabajo colaborativo. Asociación Oaxaqueña de Psicología Lecturas de metodología de la Investigación. Recuperado de: http://www.conductitlan.net/investigacion_cientifica_en_psicologia/congresos_cientificos_recomendaciones_trabajo_colaborativo.pdf

Albaladejo Mayordomo, Tomás. (1998). Teoría de los mundos posibles y macro estructura narrativa. Alicante: Publicaciones de la Universidad de Alicante.

Barahona, Miguel. (2015). La utopía retratada en paradojas. De lo particular a lo colectivo en retratos de una época de Evaristo López Rojas. En Martínez Paúl. Evaristo López Rojas. Retratos de una época. (84-121) Tegucigalpa: UNAH.

(2014). Retratos identitarios. Una propuesta de la interpretación para las imágenes del archivo Juan Pablo Martell. En Martínez, Paúl. Juan Pablo Martell. Fondo Documental de Fotografía.( 30-79).Tegucigalpa: UNAH.

(2014). Literatura de viajes para la Honduras decimonónica: visiones, invenciones e intervenciones. Representaciones, alteridad y contexto colonialista en Exploraciones y Aventuras. Revista Ciencia y Tecnología, 14, 99-114

(2011). La decodificación semiótica del grafiti: espacio y Lenguaje. En Las imágenes del grafiti: enunciación, narratividad y espacio.(33-46) Tegucigalpa: Centro Cultural de España en Tegucigalpa.

(2011). El tejido discursivo de una subjetividad: nota sobre la identidad. Revista Ciencia y Tecnología, 8, 82-91.

(2010). Travesías e imaginarios urbanos en exploraciones y aventuras en Honduras. Revista Ciencia y Tecnología, 7, 47-62.

(2010). Revelar y rebelar: transición de la modernidad a la posmodernidad en el arte fotográfico hondureño (1990-2009). En Leyva, Héctor (Comp.). Actas del segundo congreso centroamericano de estudios culturales 2009. (210-241)Tegucigalpa, Honduras. Editorial Acerca.

(2009). A propósito del viaje. Analogía y subjetividad en exploraciones y aventuras en Honduras. Revista Yaxkin, (25)1, 131-162.

(2009). A través de Madeira, las Antillas y Centroamérica de Jégor Von Sivers. Yaxkin, (25)1, 131-162.

Benet Rodríguez, Mikhail; López Torres, Lázaro; Leiva Rangel, Rafael; Hernández Pérez, Esther; Miranda Pérez, Yusimy y García Alpizar, Beatriz. (2010). El financiamiento de la investigación científica en las universidades de las Ciencias Médicas de Cuba. Realidades, retos y aspectos legales. MediSur, 8(2), 31-33. Recuperado de: http://scielo.sld.cu/scielo.php?script=sci_arttext\&pi

Cáceres Castellanos, Gustavo. (2014). La importancia de publicar los resultados de 
investigación. Revista Facultad de Ingeniería, (23), 37, 7-8. Universidad Pedagógica y Tecnológica de Colombia.

Cálix Lanza, Wendy. (2015). La construcción del paisaje en la literatura de viajes en Honduras durante los siglos XIX y XX. Revista Portal de la Ciencia, 8, 123-138. (2014). Miradas encontradas: estudio de género en el hombre de la guerra en Trilogía de Centroamérica de Javier Reverte. Istmo, Revista de estudios culturales,27-28(1-7). Recuperado de: http://istmo.denison.edu/n27-28/proyectos/13_calix_wendy_form.pdf.

Cano, Rafael. (1992). Introducción al análisis filológicos de textos. En Manuel Ariza Viguera. (Coord.). Problemas y métodos en análisis de textos In memoriam Antonio Aranda. España: Universidad de Sevilla.

Hernández, Hilcia. (2014). Actitudes lingüísticas en Honduras. Un estudio sociolingüístico sobre el español de Honduras frente al de otros países de habla hispana. En Chiquito, Ana Beatriz y Quesada Pacheco, Miguel Ángel. Actitudes lingüísticas de los hispanohablantes hacia el idioma español y sus variantes (715-792).Noruega: Bergen Language and Linguistic Studies (BeLLS).

Magariños de Morentin, Juan Ángel. Proyecto La Universidad de la Calle. Recuperado de: http://www.universidad-de-la-calle.com/Proyecto.html

Martínez, Paúl. (2015). Raúl Agüero Vega, rescatando la memoria visual del siglo XX. Revista Arte y cultura, Centro de Arte y Cultura, UNAH. II (1), 54-66.

(2015). El señor de Salamé. En Miradas al Arte 2014. (38-49). Tegucigalpa, Honduras: CAC-UNAH.

(2015). Una visita a los indios de Guajiquiro, Ephraim George Squier. En Miradas al Arte. (78-89) Tegucigalpa, Honduras: CAC-UNAH.

(2014). D. José Sotero Lazo, pluma y tinta que retrataron la nación del siglo XIX. En Miradas al Arte. (48-55) Tegucigalpa, Honduras: CAC-UNAH.

(2014). Memorias, medio siglo en fotografías. En Miradas al Arte. (64-71) Tegucigalpa, Honduras: CAC-UNAH.

Reynaga Obregón, Sonia y Farfán Flores, Pedro Emiliano (2004). Redes académicas... potencialidades académicas. Recuperado de: http://www.anuies.mx/Reynaga_ObregonFarfan redes_Academicas.pdf

Tamayo y Tamayo, Mario. (2014). El proceso de la investigación científica. México: Editorial Limusa.

Vargas Llosa, Mario. (1990). La literatura es fuego. Contra viento y marea. Barcelona: Seix Barral. 